\section{Stopping treatment in patients with hypertension}

\section{Malcolm Aylett, Stuart Ketchin}

Glendale Surgery, Wooler, Northumberland NE71 6DN

Malcolm Aylett, FRCGP, general practitioner

Stuart Ketchin, MRCGP, general practitioner

Correspondence to: Dr Aylett.

BMJ 1991;303:345 drugs in selected patients.
It is standard teaching that once treatment for hypertension is started it will be necessary for life..$^{12}$ It is assumed that patients who stop their drugs will relapse, yet anecdotal evidence suggests that hypertension does not always recur. Records of untreated patients may show a series of previous high blood pressure readings and non-compliant patients remain normotensive. We had observed several such cases, and we decided to try to discontinue antihypertensive

\section{Subjects, methods, and results}

Our practice, which comprises 1550 patients, is in a rural area with a low population turnover and an adult age-sex and social class distribution similar to that in the United Kingdom as a whole. We used the British Hypertension Working Party's diagnostic criteria for hypertension ${ }^{3}-\mathrm{a}$ diastolic blood pressure (Korotkoff phase $\mathrm{V}$ ) sustained above $100 \mathrm{~mm} \mathrm{Hg}$ for three or more readings - to determine whether to start antihypertensive treatment. Twelve per cent of adults aged 40-64 years in our practice were receiving antihypertensive drugs. Patients with no end organ damage and who were taking only one drug and had consistently good control were entered into the trial

Nine patients entered the trial. Three patients had been treated for more than 10 years, five for four to nine years, and one for two years. Though all measurements were made with the same type of sphygmomanometer and all the readings at diagnosis

Average blood pressure $(\mathrm{mm} \mathrm{Hg})^{\star}$ in patients with hypertension at time of diagnosis and before and after stopping treatment

\begin{tabular}{|c|c|c|c|c|c|c|c|c|}
\hline \multirow{2}{*}{$\begin{array}{c}\text { Case } \\
\text { No }\end{array}$} & \multirow[b]{2}{*}{ Sex } & \multirow{2}{*}{$\begin{array}{l}\text { Age at diagnosis } \\
\text { (years) }\end{array}$} & \multicolumn{2}{|c|}{ At diagnosis } & \multicolumn{2}{|c|}{ Before stopping treatment } & \multicolumn{2}{|c|}{$>1$ Year after stopping treatmen } \\
\hline & & & Systolic & Diastolic & Systolic & Diastolic & Systolic & Diastolic \\
\hline 1 & M & 53 & 162 & 106 & 128 & 82 & 144 & 89 \\
\hline 2 & $\mathrm{~F}$ & 65 & 170 & 107 & 138 & 76 & 173 & 85 \\
\hline 3 & $\mathrm{~F}$ & 48 & 200 & 110 & 148 & 85 & 163 & 87 \\
\hline 4 & $\mathrm{~F}$ & 51 & 166 & 118 & 140 & 85 & 134 & 90 \\
\hline 5 & $\mathrm{~F}$ & 50 & 165 & 106 & 149 & 85 & 152 & 88 \\
\hline 6 & $\mathrm{~F}$ & 50 & 190 & 119 & 147 & 87 & 150 & 89 \\
\hline 7 & $\mathrm{~F}$ & 54 & 166 & 109 & 144 & 85 & 149 & 90 \\
\hline 8 & M & 51 & 165 & 103 & 140 & 81 & 151 & 90 \\
\hline 9 & $\mathrm{M}$ & 62 & 185 & 106 & 159 & 81 & $194+$ & $104 \dagger$ \\
\hline
\end{tabular}

*All blood pressure values are means of three readings.

tReadings taken soon after stopping treatment. Drugs were restarted. were well within our diagnostic criteria, misdiagnosis cannot be ruled out.

During the trial we measured blood pressure using mercury sphygmomanometers with $35 \mathrm{~cm}$ cuffs. We both used the same recording protocol and had taken part in the same relevant educational programme. All machines were checked regularly and calibrated at least annually.

All patients were followed up for two years after stopping treatment. One relapsed after two months, but the remaining eight continued to have normal blood pressure (table).

\section{Comment}

We found no reports of hypertensive patients stopping treatment in European centres. American workers use different diagnostic criteria and their work is difficult to compare with European standards.

Less than $6 \%$ of hypertensive patients are thought to have secondary hypertension. ${ }^{4}$ Obesity is an obvious cause of artefactual hypertension, and high alcohol consumption may account for $10-30 \%$ of cases. ${ }^{5}$ Other reversible causes are less well documented, although depression has been suggested to be important. ${ }^{2}$

Transient stress is a common cause of raised blood pressure, which may persist over several readings. There is no clear dividing line between transient stress and mild agitated depression, and in many patients with reversible hypertension the cause may have been stress. The assumption that hypertension must be treated for life should be questioned. Sustained life stress might be an important factor in some cases.

In 1987 over two million patients were treated for hypertension in the United Kingdom at a cost in drugs alone of $£ 104$ million. Stopping the treatment of only a small proportion of patients would save much money and appreciably reduce the workload of general practice and hospitals. Implications for prescribing budgets are obvious. Many patients would be relieved of the necessity of taking drugs and for some the quality of life would be improved. Larger studies of the effect of discontinuing antihypertensive drugs are needed.

We thank Dr Sam Jachuck for valuable advice and colleagues at Glendale Surgery for their help.

Wetherall DJ, Leddingham JCG, Worrell DA, eds. Oxford textbook of medicin 2nd ed. Oxford: Oxford University Press, 1987:13.360-96.

2 Hart JT. Hypertension. 2nd ed. London: Churchill Livingstone, 1987:132.

3 British Hypertension Working Party. Treating mild hypertension: principal results. BMF 1989;298:694

4 Berglund G. Prevalence of primary and secondary hypertension: studies in a random population sample. $B M F$ 1976;ii:554-6.

Saunders JB. Alcohol: an important cause of hypertension? BMF 1987;294: 1045 .

(Accepted 24 April 1991)

\section{Department of Community \\ Health and General \\ Practice, University of \\ Kuopio, PO Box 1627, \\ SF-70211 Kuopio, Finland \\ Markku Seuri, senior lecturer in occupational health and general practice}

BM于 1991;303:345-6

\section{Risk of appendicectomy in occupations entailing contact with pigs}

\section{Markku Seuri}

Yersinia bacteria are one possible group of microorganisms which might cause appendicitis. ${ }^{1}$ In a recent study yersinia infection was found in $31 \%$ of patients with acute appendicitis. ${ }^{2}$ Moreover, the most common form of yersinia infection - acute intestinal infection often mimics appendicitis, leading to the removal of an innocent appendix. ${ }^{3}$

Yersinia spp are common in swine in various parts of the world, and at least $35 \%$ of pigs slaughtered in south western parts of Finland were found to be infected. ${ }^{+}$ Abattoir workers reportedly have an increased risk of yersinia infections. ${ }^{5}$ So far as I know work related exposures have never been considered in the context of appendicitis or appendicectomy, and I therefore decided to conduct a postal survey among pig farmers, abattoir workers, and farmers not exposed to pigs, asking if their appendixes had been removed.

\section{Subjects, methods, and results}

The study included 172 slaughterhouse floor workers from six pig processing abattoirs in central and northern Finland, 270 pig farmers, and 310 grain or berry farmers who were not involved with meat production and who lived in the eastern part of 